\title{
Longitudinal association between lung function and health-related quality of life in cystic fibrosis
}

\author{
Janice Abbott, ${ }^{1}$ Margaret A Hurley, ${ }^{2}$ Alison M Morton, ${ }^{3}$ Steven P Conway ${ }^{3}$
}

${ }^{1}$ School of Psychology, University of Central Lancashire, Preston, UK ${ }^{2}$ School of Health, University of Central Lancashire, Preston, UK ${ }^{3}$ Adult Cystic Fibrosis Unit, St James' Hospital, Leeds, UK

\section{Correspondence to} Professor Janice Abbott, School of Psychology, University of Central Lancashire, Darwin Building, Preston PR1 2HE, UK; jabbott@uclan.ac.uk

Received 10 August 2012 Revised 12 October 2012 Accepted 18 October 2012 Published Online First 9 November 2012

\begin{abstract}
Background Lung function is an important indicator of cystic fibrosis disease status and those with better forced expiratory volume in $1 \mathrm{~s}\left(\mathrm{FEV}_{1}\right) \%$ predicted have tended to report a better health-related quality of life (HRQoL)

in cross-sectional studies. The relationship between lung function and HRQoL over time is unknown. This work assesses the natural progression of HRQoL reporting over many years and compares assessments across a whole decade and evaluates the relationship between lung function and HRQoL longitudinally.

Methods Demographic (age, gender), clinical (FEV $\%$ predicted, body mass index, diabetes, Burkholderia cepacia complex, intravenous access device and nutritional status) and HRQoL (Cystic Fibrosis Quality of Life Questionnaire) variables were obtained every 2 years over a 12-year period (seven time points from 1998 to 2010).

Results HRQoL and lung function declined slowly over time and significant decade changes were observed for $\mathrm{FEV}_{1} \%$ predicted and the nine domains of the Cystic Fibrosis Quality of Life Questionnaire. The results of random coefficient modelling indicated that, at the population level, decreasing $\mathrm{FEV}_{1} \%$ predicted was associated with decreasing HRQOL after adjusting for confounding variables. However, the percentage of patients for whom a decrease in lung function was associated with a decrease in $\mathrm{HRQ}$ oL differed according to the quality of life domain.

Conclusions HRQOL and $\mathrm{FEV}_{1} \%$ predicted decline slowly; nevertheless, a decrease in lung function predicted a decrease in HRQoL over time.
\end{abstract}

\section{INTRODUCTION}

Cystic fibrosis (CF) is the most common lethal autosomal recessive condition in the white population. ${ }^{1}$ Improvements in care have led to median survival reaching the late $30 \mathrm{~s}^{2}$ With increasing age, however, a high proportion of people develop diabetes mellitus and some patients develop a variety of complications including pneumothorax, haemoptysis and osteoporosis. The daily treatment regimen of chest physiotherapy, nutrition, exercise and oral, inhaled and intravenous medication is burdensome, complex and time-consuming. The progressive nature of CF disease and the demanding treatment burden ${ }^{3} 4$ have the potential to encroach on daily living and to impact on the person's health-related quality of life (HRQoL). HRQoL measurement allows the inclusion of the patient's perspective in research and clinical practice. ${ }^{5}$ The insights that patients have concerning their health and how they report these are important, given that aspects of HRQoL have been shown to be independent predictors of survival. ${ }^{6}$

\section{Key messages}

What is the key question?

- Health-related quality of life (HRQoL) measures are increasingly being used to evaluate the effectiveness of interventions but there are scant data as to how HRQoL scores naturally vary over time. This work evaluates the relationship between HRQoL and lung function longitudinally and addresses the question 'Does HRQoL reporting follow the trend of FEV1\% predicted?'

\section{What is the bottom line?}

- FEV1\% predicted and HRQoL decline slowly, nevertheless, a decrease in lung function predicts a decrease in HRQoL over time.

\section{Why read on?}

- This work provides the first longitudinal HRQoL data for cystic fibrosis that assesses the natural progression of HRQoL reporting over many years, providing a benchmark to inform data interpretation and clinical relevance.

Forced expiratory volume in $1 \mathrm{~s}\left(\mathrm{FEV}_{1}\right) \%$ predicted is an important indicator of disease status, and those with better lung function tend to report a better HRQoL. The most convincing data come from analyses of known groups undertaken during the evaluation of the CF-specific HRQoL instruments. ${ }^{7-9}$ Differences between disease severity groups (mild: $\mathrm{FEV}_{1} \%$ predicted $\geq 70 \%$; moderate: $\mathrm{FEV}_{1} \%$ predicted 40-69\%; severe: $\mathrm{FEV}_{1} \%$ predicted <40\%) were observed across many HRQoL domains. Those with mild disease generally reported a better HRQoL than those with severe disease. However, studies have demonstrated weak to moderate correlations between HRQoL and lung function in children and adults, ${ }^{7-12}$ with weaker correlations often found in studies employing generic rather than CF-specific scales. Even though $\mathrm{FEV}_{1} \%$ predicted was positively associated with HRQoL domains in multivariate analyses, it accounted for only a small proportion of variability in HRQoL scores. ${ }^{11-14}$ This cross-sectional work suggests that very large differences in $\mathrm{FEV}_{1} \%$ predicted would be required to predict even modest differences in HRQoL scores.

HRQoL instruments are increasingly being used to evaluate the effectiveness of interventions and their use in routine clinical management has been 
shown to be feasible, ${ }^{15}$ but there are scant data as to how HRQoL scores naturally vary over time. A few studies have assessed changes in HRQoL and lung function over 1-2 years. The most salient finding was the stability of HRQoL over this time and its independence from the course of $\mathrm{FEV}_{1} \%$ predicted. $^{15}{ }^{16}$ Similarly, data from the US Epidemiologic Study of Cystic Fibrosis showed that, over a 1-year period, changes in both clinical variables and HRQoL were small. ${ }^{17}$

The cross-sectional nature of most studies does not allow the assessment of cause and effect. The initial aim of this work was to provide the first true prospective longitudinal HRQoL data for CF, to assess the natural progression of HRQoL reporting over many years and to compare assessments across a whole decade. A further objective was to evaluate the relationship between HRQoL and lung function longitudinally and to address the question: 'Do HRQoL domains follow the trend of $\mathrm{FEV}_{1} \%$ predicted?' Our hypothesis, based on previous work, was that HRQoL is independent of $\mathrm{FEV}_{1} \%$ predicted.

\section{METHODS}

\section{Subjects and procedure}

All patients aged 16 years or older who attended a large Adult Cystic Fibrosis Centre in the UK were approached to take part in the study. Demographic, clinical and HRQoL variables were initially obtained during the patient's routine annual CF assessment. The centre followed standard treatment protocols and annual reviews were undertaken as close to the patient's birthday as possible, predominantly when the patient was clinically stable. They were followed-up every 2 years over a 12-year period (seven time points from 1998 to 2010). At each time point patients provided consent for their participation in accordance with ethical committee approval. The Cystic Fibrosis Quality of Life Questionnaire (CFQoL) was mailed out for completion prior to clinic appointments at which demographic and clinical variables were recorded. Not all patients entered the study at time point 1 (T1), but joined the study at later time points (T2-T7).

\section{Measures}

At each time point demographic, clinical and HRQoL variables were collected. Age and gender, $\mathrm{FEV}_{1} \%$ predicted, body mass index (BMI), whether the person had diabetes, Burkholderia cepacia complex or an intravenous access device were recorded. Nutritional status (no oral calorie supplements, prescribed oral calorie supplements or prescribed enteral tube feeds) and lung transplantation were also documented. These variables describe the characteristics of the sample and include known predictors of decline in $\mathrm{FEV}_{1} \%$ predicted. ${ }^{18} 19$ They have also been shown to relate to HRQoL, but only in cross-sectional studies. ${ }^{14} 15$ 20-22

Quality of life was measured using the CFQoL. ${ }^{9}$ The CFQoL was developed and validated in the UK and was therefore the most appropriate CF-specific HRQoL measure for this UK sample. The instrument measures nine domains of functioning: Physical functioning, Social functioning, Emotional responses, Treatment issues, Chest symptoms, Body image, Interpersonal relationships, Career concerns and Concerns for the future. The psychometric properties of the instrument are good. Internal reliability of the domains was demonstrated using Cronbach's alpha coefficients (range 0.72-0.92, median 0.89) and item to total domain score correlations. Concurrent validity with three appropriate SF-36 domains (range $r=0.64-0.74$ ), known groups validity between different levels of disease severity, sensitivity across transient changes in health (effect size range, $\mathrm{d}=0.56-1.95$ ) and test-retest reliability $(r=0.74-0.96$, median 0.91$)$ were found to be robust. ${ }^{9}{ }^{10}$ Each domain has a minimum score of $0 \%$ and a maximum score of $100 \%$, with higher scores reflecting a better quality of life.

\section{Statistical analyses}

Patient assessments were described by summary statistics. Long-term changes were summarised at time points separated by 10 years; mostly $\mathrm{T} 2$ and $\mathrm{T} 7$, otherwise $\mathrm{T} 1$ and $\mathrm{T} 6$. Long-term changes were tested for significance using $t$ tests.

The longitudinal relationships between the nine domains of CFQoL and $\mathrm{FEV}_{1} \%$ predicted were explored using regression models with fixed and random coefficients. These models are an established methodology in longitudinal studies ${ }^{23} 24$ since they allow the observations on one individual to be explained by an individual regression coefficient which arises from a population of normally distributed coefficients across individuals. For each HRQoL domain, CFQoL $=100 \times S / N$ where $S$ was the domain score and $N$ was the maximum score. Maximum scores were: Physical functioning (50), Social functioning (20), Emotional responses (40), Treatment issues (15), Chest symptoms (20), Body image (15), Interpersonal relationships (50), Concerns for the future (30) and Career concerns (20). The relationship between $\mathrm{CFQ}$ oL domain and $\mathrm{FEV}_{1} \%$ predicted was adjusted for the confounding effects of age, gender, BMI, diabetes mellitus and nutritional status by including these variables in the models. Statistical analysis of HRQoL presents challenges because of the well-understood 'ceiling effects' for HRQoL measures which are limited above by $100 \%{ }^{25}$ and because domain scores are discrete measures only taking values corresponding to whole numbers. There is particular difficulty when the maximum score is low-for example, for Chest symptoms which can take only the values $100 \%, 95 \%, 90 \%$ etc.

Binomial regression with fixed and random coefficients was chosen as an appropriate analysis because the binomial is a discrete distribution for scores having a predetermined maximum. Binomial regression predicts within the range $0-100 \%$ because the covariates predict the logistic transformation of HRQoL, similar to logistic regression analysis. This approach was assessed initially by fitting binomial regression models for individual participants and then exploring the distribution of the coefficients, and the approach was found to be suitable. Models were fitted using the software MLwiN. ${ }^{26}$

The models estimated the means and variances of the random coefficients for $\mathrm{FEV}_{1} \%$ predicted, BMI and the intercept. Gender, diabetes mellitus and nutritional status were included as fixed effects. Age was included as a fixed effect because age changes deterministically with time. The random coefficients were tested to check whether each should be retained as random or could be included as fixed.

The normal distribution for the random coefficient for $\mathrm{FEV}_{1} \%$ predicted provided evidence of whether HRQoL was related to $\mathrm{FEV}_{1} \%$ predicted longitudinally. If the mean of the normal distribution was significantly greater than zero, then the participant population showed overall a positive mean coefficient for the relationship between the CFQoL domain and $\mathrm{FEV}_{1} \%$ predicted after adjusting for the confounding variables. A positive coefficient implied that a declining HRQoL domain was associated with declining $\mathrm{FEV}_{1} \%$ predicted. The proportion of the participant population exhibiting a positive coefficient was estimated from the fitted normal distribution and 95\% CIs were obtained by computer simulation.

Thus, the random coefficients approach permitted an informative answer to the question: 'Do CFQoL domains follow the trend of $\mathrm{FEV}_{1} \%$ predicted?' The answer was both a 'yes' or 'no' 
Table 1 Characteristics of the samples at each time point

\begin{tabular}{|c|c|c|c|c|c|c|c|}
\hline Time points & $\mathrm{T} 1$ & T2 & T3 & T4 & T5 & T6 & $\mathrm{T7}$ \\
\hline Sample size & 116 & 145 & 105 & 95 & 91 & 107 & 137 \\
\hline Clinic population size & 220 & 245 & 285 & 286 & 315 & 336 & 355 \\
\hline Men & $45(39 \%)$ & $63(43 \%)$ & $45(43 \%)$ & $39(41 \%)$ & $33(36 \%)$ & $51(48 \%)$ & $61(44 \%)$ \\
\hline Women & $71(61 \%)$ & $82(57 \%)$ & $60(57 \%)$ & $56(59 \%)$ & $58(64 \%)$ & $56(52 \%)$ & 76 (56\%) \\
\hline $\begin{array}{l}\text { Age, mean (SD) } \\
\text { [Range] }\end{array}$ & $\begin{array}{l}25.1(6.7) \\
{[16-50]}\end{array}$ & $\begin{array}{l}24.7(7.3) \\
{[14-51]}\end{array}$ & $\begin{array}{l}26.3(7.8) \\
{[14-53]}\end{array}$ & $\begin{array}{l}28.6(7.3) \\
{[16-51]}\end{array}$ & $\begin{array}{l}29.7(8.1) \\
{[18-50]}\end{array}$ & $\begin{array}{l}31.6(7.5) \\
{[20-55]}\end{array}$ & $\begin{array}{l}33.7(7.8) \\
{[22-57]}\end{array}$ \\
\hline $\begin{array}{l}\mathrm{FEV}_{1} \% \text {, mean }(\mathrm{SD}) \\
\text { [Range] }\end{array}$ & $\begin{array}{l}58.5 \%(24.4) \\
{[14.0-133.0 \%]}\end{array}$ & $\begin{array}{l}59.6 \%(23.9) \\
{[12.0-128.0 \%]}\end{array}$ & $\begin{array}{l}60.8 \%(24.4) \\
{[16.0-128.0 \%]}\end{array}$ & $\begin{array}{l}59.6 \%(22.9) \\
{[20.0-113.0 \%]}\end{array}$ & $\begin{array}{l}57.0 \%(24.8) \\
{[16.0-109.0 \%]}\end{array}$ & $\begin{array}{l}57.3 \%(23.9) \\
{[14.0-119.0 \%]}\end{array}$ & $\begin{array}{l}56.9 \%(23.3) \\
{[14.0-114.0 \%]}\end{array}$ \\
\hline Mild disease, $\mathrm{N}(\%)$ & $41(35 \%)$ & $55(38 \%)$ & $40(38 \%)$ & $30(32 \%)$ & $30(33 \%)$ & $32(30 \%)$ & $38(28 \%)$ \\
\hline Moderate disease, N (\%) & $42(36 \%)$ & $58(40 \%)$ & $39(37 \%)$ & $44(46 \%)$ & $32(35 \%)$ & $46(43 \%)$ & $63(46 \%)$ \\
\hline Severe disease, N (\%) & $33(29 \%)$ & $32(22 \%)$ & $26(25 \%)$ & $21(22 \%)$ & $29(32 \%)$ & $29(27 \%)$ & $36(26 \%)$ \\
\hline $\begin{array}{l}\text { BMI, mean (SD) } \\
\text { [Range] }\end{array}$ & $\begin{array}{r}21.4(3.1) \\
{[15.6-30.2]}\end{array}$ & $\begin{array}{r}21.5(2.9) \\
{[16.0-30.1]}\end{array}$ & $\begin{array}{r}21.9(3.1) \\
{[15.1-33.1]}\end{array}$ & $\begin{array}{r}22.0(2.7) \\
{[16.3-29.2]}\end{array}$ & $\begin{array}{r}22.0(3.2) \\
{[13.3-33.7]}\end{array}$ & $\begin{array}{r}21.9(3.2) \\
{[16.8-34.2]}\end{array}$ & $\begin{array}{r}21.3(3.2) \\
{[16.1-33.8]}\end{array}$ \\
\hline IV access device & $47(41 \%)$ & $72(50 \%)$ & $50(48 \%)$ & $46(48 \%)$ & $51(56 \%)$ & $66(62 \%)$ & $85(62 \%)$ \\
\hline B cepacia complex & $7(6 \%)$ & $13(9 \%)$ & $10(10 \%)$ & $10(11 \%)$ & $4(4 \%)$ & $10(9 \%)$ & $8(6 \%)$ \\
\hline CF-related diabetes & $26(22 \%)$ & $49(34 \%)$ & $38(36 \%)$ & $32(34 \%)$ & $36(40 \%)$ & $49(46 \%)$ & $69(50 \%)$ \\
\hline Oral nutritional supplements & $44(38 \%)$ & $45(31 \%)$ & $36(34 \%)$ & $25(26 \%)$ & $30(33 \%)$ & 37 (35\%) & $44(32 \%)$ \\
\hline Enteral tube feeds & $24(21 \%)$ & $27(19 \%)$ & $10(10 \%)$ & $16(17 \%)$ & $9(10 \%)$ & $16(15 \%)$ & $26(19 \%)$ \\
\hline Post-transplant & $11(9 \%)$ & $14(10 \%)$ & $12(11 \%)$ & $17(18 \%)$ & $14(15 \%)$ & $13(12 \%)$ & $18(13 \%)$ \\
\hline
\end{tabular}

$\mathrm{BMI}$, body mass index; $\mathrm{CF}$, cystic fibrosis; $\mathrm{FEV}_{1} \%$, forced expiratory volume in $1 \mathrm{~s}$; IV, intravenous.

for the whole cohort, and also an estimate of the proportion of patients with CF for whom the answer was in the affirmative.

\section{RESULTS}

Demographic and clinical characteristics of the sample for the seven time points are presented in table 1, together with the clinic total population size at each time point. A total of 234 patients entered the study. The numbers of time points at which patients were assessed are given in table 2. The length of time patients remained in the study (time between first and last assessment) are provided in table 3 together with the number of patients who died during the study period. The median age of death was 28 years (IQR 24-35). Patients with only one time point were still included in the analyses because this improved the estimation of the random intercept and hence contributed to the precision of the longitudinal coefficients.

\section{Changes in $\mathrm{FEV}_{1} \%$ predicted and CFQoL domains over a decade}

The database contained 91 patients (40 men) with assessments separated by precisely 10 years. Table 4 presents the mean changes for age, clinical variables and CFQoL domains for men and women over one decade. As a visual example, figures 1 and 2 illustrate the change in $\mathrm{FEV}_{1} \%$ predicted and Chest symptoms

Table 2 Number of times (time points) patients were assessed

\begin{tabular}{lc}
\hline Number of assessments & Number of patients \\
\hline 1 & 54 \\
2 & 51 \\
3 & 31 \\
4 & 32 \\
5 & 25 \\
6 & 19 \\
7 & 22 \\
Total patients & 234 \\
\hline
\end{tabular}

for men and women, respectively, and for most patients the change is a decline. Significant decade changes were observed for $\mathrm{FEV}_{1} \%$ predicted and the nine domains of the CFQoL, but not for BMI (men, $\mathrm{p}=0.087$; women, $\mathrm{p}=0.305$ ). There were no significant differences between men and women except for BMI $(p=0.046)$, but the actual difference was small and not deemed clinically relevant.

\section{Relationship between $\mathrm{FEV}_{1} \%$ predicted and $H R Q O L$ over time}

Table 5 presents the results of the random coefficient modelling. The $\mathrm{FEV}_{1} \%$ predicted variance-covariance estimates were significant for all domains except Body image, and this confirmed that $\mathrm{FEV}_{1} \%$ predicted was a random effect for all the domains except possibly for Body image. The $\mathrm{FEV}_{1} \%$ predicted coefficient mean was positive and highly significantly different from zero for all domains except Body image. Hence, at the population level, decreasing $\mathrm{FEV}_{1} \%$ predicted was associated with decreasing HRQoL even after adjusting for all the other confounding variables in the models.

The statistical analysis assumed patients had a personal coefficient of change in $\mathrm{HRQoL}$ with changing $\mathrm{FEV}_{1} \%$ predicted. The analysis estimated the mean coefficient of the CF

Table 3 Number of years between first and last assessment and number of patients who died during the study

\begin{tabular}{lll}
\hline Years in study & Number of patients & Number of deaths \\
\hline$<2$ & 54 & 27 \\
2 & 22 & 10 \\
4 & 24 & 5 \\
6 & 14 & 3 \\
8 & 18 & 4 \\
10 & 38 & 1 \\
12 & 64 & 0 \\
Total patients & 234 & 50 \\
\hline
\end{tabular}


Table 4 Change over one decade in age, body mass index (BMI), forced expiratory volume in $1 \mathrm{~s}\left(\mathrm{FEV}_{1}\right) \%$ predicted, diabetes mellitus, nutritional supplements, enteral feeding and the nine domains of the Cystic Fibrosis Quality of Life Questionnaire (CFQoL) for 91 patients with cystic fibrosis (CF) in the cohort (40 men and 51 women) with assessments separated by 10 years*

\begin{tabular}{|c|c|c|c|c|c|c|}
\hline & \multicolumn{2}{|c|}{ Start of decade } & \multicolumn{2}{|c|}{ End of decade } & \multicolumn{2}{|c|}{ Decade change } \\
\hline \multicolumn{7}{|c|}{ Age (years), mean (SD) } \\
\hline All & 25.1 & $(7.5)$ & 34.9 & (7.6) & 9.8 & $(0.5)$ \\
\hline Men & 24.5 & (7.6) & 34.3 & (7.7) & 9.8 & $(0.7)$ \\
\hline Women & 25.5 & $(7.5)$ & 35.4 & $(7.5)$ & 9.9 & $(0.3)$ \\
\hline \multicolumn{7}{|c|}{$\mathrm{FEV}_{1} \%$, mean (SD) } \\
\hline All & 61.9 & (22.1) & 53.1 & (22.5) & -8.8 & (18.3) \\
\hline Men & 65.9 & (20.1) & 55.3 & (22.2) & -10.6 & (13.4) \\
\hline Women & 58.7 & (23.2) & 51.4 & (22.9) & -7.3 & (21.4) \\
\hline \multicolumn{7}{|c|}{ BMI, mean (SD) } \\
\hline All & 21.4 & $(2.8)$ & 21.5 & $(2.9)$ & 0.1 & $(1.7)$ \\
\hline Men & 21.6 & $(3.0)$ & 22.1 & $(3.3)$ & 0.5 & $(1.8)$ \\
\hline Women & 21.3 & $(2.7)$ & 21.1 & $(2.5)$ & -0.2 & $(1.7)$ \\
\hline \multicolumn{7}{|c|}{ Diabetes, n (\%) } \\
\hline All & 31 & (34) & 52 & (57) & 21 & (23) \\
\hline Men & 10 & (25) & 24 & (60) & 12 & (35) \\
\hline Women & 21 & (41) & 28 & (55) & 7 & (14) \\
\hline \multicolumn{7}{|c|}{ Nutritional supplements, $\mathrm{n}(\%)$} \\
\hline All & 31 & (34) & 33 & (36) & 2 & (2) \\
\hline Men & 20 & $(50)$ & 17 & (43) & -3 & $(-7)$ \\
\hline Women & 11 & (22) & 16 & (31) & 5 & (9) \\
\hline \multicolumn{7}{|c|}{ Enteral feeding, n (\%) } \\
\hline All & 13 & (14) & 17 & (19) & 4 & (5) \\
\hline Men & 5 & (12) & 8 & (16) & 3 & (4) \\
\hline Women & 8 & (16) & 9 & (18) & 1 & (2) \\
\hline \multicolumn{7}{|c|}{ Physical functioning, mean (SD) } \\
\hline All & 86.8 & (15.8) & 78.8 & $(21.8)$ & -8.0 & (16.7) \\
\hline Men & 89.3 & (14.6) & 81.7 & (19.2) & -7.6 & (13.7) \\
\hline Women & 84.9 & (16.6) & 76.5 & (23.5) & -8.4 & (18.9) \\
\hline \multicolumn{7}{|c|}{ Social functioning, mean (SD) } \\
\hline All & 87.6 & (16.4) & 78.4 & $(26.2)$ & -9.2 & (21.9) \\
\hline Men & 87.8 & (17.6) & 81.6 & (21.8) & -6.2 & (17.7) \\
\hline Women & 87.5 & (15.5) & 75.8 & (29.1) & -11.7 & (24.6) \\
\hline \multicolumn{7}{|c|}{ Emotional responses, mean (SD) } \\
\hline All & 80.9 & (20.5) & 72.6 & (23.1) & -8.3 & (18.8) \\
\hline Men & 83.8 & (21.5) & 75.9 & (21.4) & -7.9 & (19.1) \\
\hline Women & 78.7 & (19.6) & 69.9 & (24.3) & -8.8 & (19.0) \\
\hline \multicolumn{7}{|c|}{ Treatment issues, mean (SD) } \\
\hline All & 80.1 & (20.6) & 66.4 & $(22.0)$ & -13.7 & (19.9) \\
\hline Men & 80.7 & (24.4) & 65.8 & $(21.8)$ & -14.9 & $(19.0)$ \\
\hline Women & 79.6 & (17.4) & 66.9 & (22.4) & -12.7 & (20.7) \\
\hline \multicolumn{7}{|c|}{ Chest symptoms, mean (SD) } \\
\hline All & 79.9 & (19.8) & 70.5 & (24.1) & -9.4 & (18.9) \\
\hline Men & 81.4 & (22.6) & 71.6 & (23.7) & -9.8 & (15.6) \\
\hline Women & 78.7 & (17.5) & 69.6 & (24.7) & -9.1 & (22.1) \\
\hline \multicolumn{7}{|c|}{ Body image, mean (SD) } \\
\hline All & 70.1 & $(23.0)$ & 64.1 & (26.1) & -6.0 & $(15.2)$ \\
\hline Men & 66.2 & $(24.2)$ & 59.1 & (26.9) & -7.1 & (17.4) \\
\hline Women & 73.3 & (21.8) & 68.0 & $(25.0)$ & -5.3 & (13.3) \\
\hline \multicolumn{7}{|c|}{ Interpersonal relationships, mean (SD) } \\
\hline All & 64.5 & $(21.9)$ & 57.7 & (25.8) & -6.8 & (22.0) \\
\hline Men & 69.0 & (22.8) & 61.8 & (25.5) & -7.2 & (22.7) \\
\hline Women & 60.9 & $(20.7)$ & 54.5 & (25.8) & -6.4 & (21.6) \\
\hline \multicolumn{7}{|c|}{ Career concerns, mean (SD) } \\
\hline
\end{tabular}

Table 4 Continued

\begin{tabular}{|c|c|c|c|c|c|c|}
\hline \multirow[b]{2}{*}{ All } & \multicolumn{2}{|c|}{ Start of decade } & \multicolumn{2}{|c|}{ End of decade } & \multicolumn{2}{|c|}{ Decade change } \\
\hline & 65.5 & (26.4) & 49.6 & (32.5) & -15.9 & (23.3) \\
\hline Men & 71.4 & $(25.4)$ & 55.8 & $(32.5)$ & -15.6 & (23.4) \\
\hline Women & 61.0 & (26.6) & 44.7 & (31.9) & -16.3 & (23.3) \\
\hline \multicolumn{7}{|c|}{ Concerns for the future, mean (SD) } \\
\hline All & 49.4 & $(25.5)$ & 36.2 & (23.4) & -13.2 & $(21.2)$ \\
\hline Men & 56.4 & $(25.1)$ & 42.0 & (25.6) & -14.4 & (21.1) \\
\hline Women & 43.9 & (24.6) & 31.7 & (20.6) & -12.2 & (21.4) \\
\hline
\end{tabular}

*The 91 patients comprised the 38 patients who had 10 years between first and last observations and 53 of the 64 patients who had 12 years between first and last observations (11 patients in the latter group were omitted because they did not have data separated by precisely 10 years).

population together with the variability (variance) of the patients' coefficients; the method did not estimate individual patient coefficients and hence could not categorise individuals as those having a positive or negative coefficient. However, because the method estimated the statistical distribution of coefficients, it did allow for the computation of the percentage of patients for whom a decrease in lung function was associated with a decrease in HRQoL, and this percentage differed according to the HRQoL domain. For over $80 \%$ of adults, a decrease in lung function predicted a decrease in Chest symptom score. For approximately $70 \%$ of patients a decline in lung function predicted a decline in Physical functioning, Social functioning, Treatment issues, Emotional responses and Career concerns. This relationship held true for over $60 \%$ of patients for Concerns for the future and Interpersonal relationships. Hence, for all domains except Body image, the majority of patients showed a relationship between declining $\mathrm{FEV}_{1} \%$ predicted and declining HRQoL in the longer term, indicating that HRQoL reporting followed the trend of $\mathrm{FEV}_{1} \%$ predicted. Approximate CIs for the percentages are given in table 5 .

\section{DISCUSSION}

This work provides the first longitudinal HRQoL data in CF that follows patients over many years, providing a natural progression of HRQoL reporting over time. Both $\mathrm{FEV}_{1} \%$ predicted and HRQoL decline slowly and, contrary to our hypothesis, a decrease in lung function was associated with a decrease in
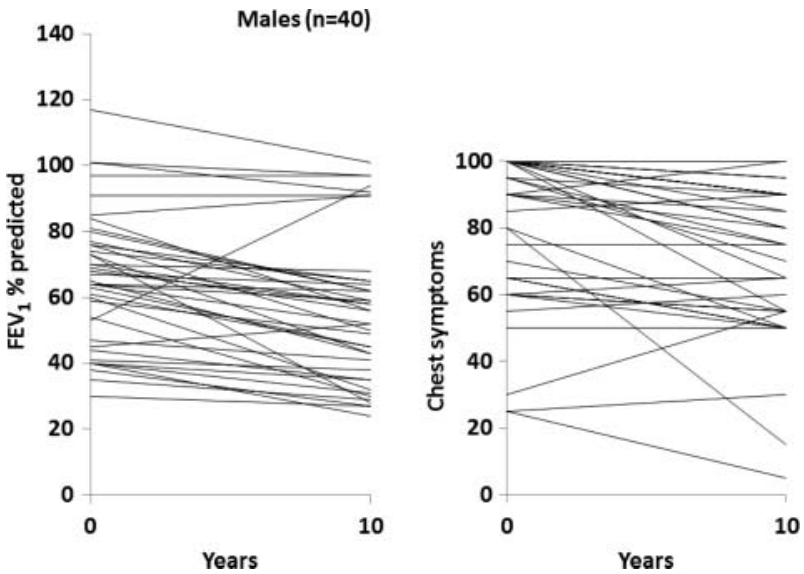

Figure 1 Change over one decade in forced expiratory volume in $1 \mathrm{~s}$ $\left(\mathrm{FEV}_{1}\right) \%$ predicted and Chest symptoms for 40 men in the cohort. 

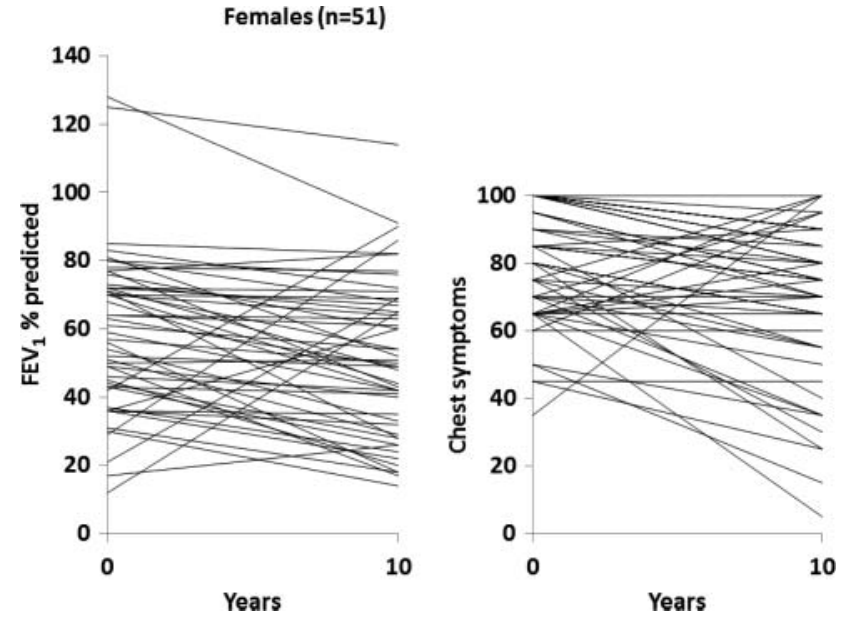

Figure 2 Change over one decade in forced expiratory volume in $1 \mathrm{~s}$ $\left(\mathrm{FEV}_{1}\right) \%$ predicted and Chest symptoms for 51 women in the cohort.

HRQoL. The changes in lung function over a decade were representative of the UK population. ${ }^{2}{ }^{18}$ BMI remained constant, and this is attributed to the exceptional longstanding gastroenterology expertise within this centre. ${ }^{27}$ The increase in CF-related diabetes (CFRD) over the decade is likely to reflect the ageing of the cohort since there has been a decrease in CFRD in this centre. ${ }^{2}$

Although HRQoL declined slowly for young adults with CF, it is noteworthy that HRQoL population norms remain constant over a comparative age span. ${ }^{28}$ With declining lung function it was not the physical aspects of HRQoL that decreased the most but the psychosocial domains of Career concerns, Concerns for the future and Treatment issues. This may be expected as treatment becomes more burdensome and employment and the future more uncertain with advancing CF disease. Interestingly, Physical functioning and Chest symptoms decreased by $8 \%$ and $9.4 \%$, respectively, over a decade, a similar decrease to $\mathrm{FEV}_{1} \%$ predicted. However, it would be an erroneous assumption to consider $\mathrm{FEV}_{1} \%$ predicted a proxy for the clinical/physical HRQoL domains. HRQoL can provide 'added value' as it can supply information not captured by other outcomes. Indeed, the Physical functioning domain of the CFQoL is an independent predictor of survival ${ }^{6}$ and, in a recent trial, only HRQoL provided additional information to lung function from several secondary endpoints. $^{29}$ It is also noteworthy that the standard deviations for $\mathrm{FEV}_{1} \%$ predicted and the $\mathrm{CFQoL}$ domains are large so, although there was a similar percentage decrease at the population level, this was not necessarily true at the individual level.

The cross-sectional data from the literature suggested that large differences in lung function were required to predict differences in HRQoL. ${ }^{11-14}$ There was also a lack of association reported over $12-18$ month periods. ${ }^{15-17}$ This is not surprising since decreases in $\mathrm{FEV}_{1} \%$ predicted and HRQoL scores are approximately $1 \%$ per year and are highly variable across individuals, as evidenced in figures 1 and 2 . It is noteworthy that similar short-term results were reported with the use of different HRQoL instruments. ${ }^{15-17}$ Whether HRQoL instruments containing different domains yield similar long-term data remains to be evaluated. HRQoL changes in response to acute clinical situations are not explicitly considered here (eg, new symptoms or improvements expected with treatments), but knowing the natural rate of change in HRQoL domains provides a
Table 5 Estimated mean and variance for the random effect of forced expiratory volume in $1 \mathrm{~s}\left(\mathrm{FEV}_{1}\right) \%$ predicted on each domain of Cystic Fibrosis Quality of Life Questionnaire (CFQoL) together with estimated \% of patients having a declining CFQoL domain with declining $\mathrm{FEV}_{1} \%$ predicted.

\begin{tabular}{llll}
\hline Domain & $\begin{array}{l}\mathrm{FEV}_{1} \% \text { predicted } \\
\text { Estimate (SE) }\end{array}$ & $\mathrm{p} \mathrm{Value}^{*}$ & $\begin{array}{l}\text { \% of patients } \\
(95 \% \mathrm{Cl})\end{array}$ \\
\hline $\begin{array}{l}\text { Physical functioning } \\
\text { Mean }\end{array}$ & $0.0217(0.0039)$ & $<0.001$ & \\
Variance & $0.0014(0.0003)$ & $<0.001$ &
\end{tabular}

Social functioning

$\begin{array}{lll}\text { Mean } & 0.0149(0.0042) & <0.001 \\ \text { Variance } & 0.0010(0.0002) & <0.001\end{array}$

Emotional responses

$\begin{array}{lll}\text { Mean } & 0.0130(0.0033) & <0.001 \\ \text { Variance } & 0.0008(0.0002) & <0.001\end{array}$

Treatment issues

$\begin{array}{llr}\text { Mean } & 0.0116(0.0033) & <0.001 \\ \text { Variance } & 0.0006(0.0002) & 0.002\end{array}$

68 (59 to 78$)$

Variance $\quad 0.0006(0.0002) \quad 0.002$

$\begin{array}{lrr}\text { Chest symptoms } & & \\ \text { Mean } & 0.0205(0.0032) & <0.001 \\ \text { Variance } & 0.0005(0.0001) & 0.003\end{array}$

68 (58 to 82$)$

Variance

$0.0005(0.0001)$

0.003

Body image

$\begin{array}{lll}\text { Mean } & 0.0019(0.0082) & 0.877\end{array}$

Variance $\quad 0.0001(0.0001) \quad 0.507$

58 (39 to 87$)$

Interpersonal relationships

$\begin{array}{lll}\text { Mean } & 0.0116(0.0032) & <0.001\end{array}$

Variance $\quad 0.0010(0.0002)<0.001$

64 (57 to 73$)$

Career concerns

$\begin{array}{lll}\text { Mean } & 0.0164(0.0032) & <0.001 \\ \text { Variance } & 0.0007(0.0002) & <0.001\end{array}$

73 (64 to 84$)$

Concerns for the future

$\begin{array}{llr}\text { Mean } & 0.0077(0.0027) & 0.044 \\ \text { Variance } & 0.0005(0.0001) & <0.001\end{array}$

64 (54 to 73$)$

${ }^{*} \chi^{2}$ test with $1 \mathrm{df}$ for the mean but with $3 \mathrm{df}$ for the variance since the variance was tested jointly with the covariance with the other two random effects in the model.

benchmark against which changes due to complications or interventions can be compared and should help to inform the clinical relevance of such data.

The decade changes (table 4) were for individuals who survived the decade, but the modelling of the relationship between HRQoL and $\mathrm{FEV}_{1} \%$ predicted was carried out using all patients who entered the study. Some of these individuals died or dropped out during the 12 years, but their available data were still included in the analyses. HRQoL reporting followed the decreasing trend of $\mathrm{FEV}_{1} \%$ predicted over time. However, the percentage of patients for whom a decrease in lung function was associated with a decrease in HRQoL differed according to the HRQoL domain. For $82 \%$ of adults a decrease in lung function was associated with a decrease in their Chest symptom score, whereas this relationship was true for only 58\% of people concerning their Body image score. For a significant minority, a 
decrease in lung function seemed not to be associated with a decrease in HRQoL domains. What differentiates these patients is unknown, but is potentially very important as some individuals had a decrease in lung function but maintained a high level of HRQoL over time, indicating that they were psychologically resilient. ${ }^{30}$ Understanding the determinants for sustaining a good HRQoL with advancing disease may help to ensure the best possible HRQoL for people with CF.

There is some evidence in the CF literature that the role of coping and mood may be important. Optimistic coping (focused, determined and optimistic beliefs about the future) and distraction coping (doing things to forget CF) emerged as significant predictors of how adults with CF report their HRQoL. Optimism was consistently associated with a superior quality of life while distraction was consistently associated with a poorer quality of life. ${ }^{31}$ Conversely, depressive symptoms were associated with a poorer HRQoL across all CFQ domains. ${ }^{32}$ Screening for and treating depression may improve HRQoL, and further robust studies using multivariate modelling are required to assess the impact of mood on HRQoL and clinical status. We await results from the International Depression and Anxiety Epidemiological Study to clarify these relationships.

A limitation of the work is that it was a single-centre study. Nevertheless, this is the first reported longitudinal data set that has enabled the evaluation of population and individual level clinical and HRQoL changes over many years. Additionally, several variables now considered to be important because they increase the rate of decline in $\mathrm{FEV}_{1} \%$ predicted were not collected. These included microbiological status (eg, Pseudomonas aeruginosa, MRSA and members of the $B$ cepacia complex $^{18} 33^{34}$ ) and the frequency of pulmonary exacerbations. ${ }^{35}$ It is also possible that patients receiving more therapies report different trajectories in HRQoL. When undertaking longitudinal work in a disease that is changing (improving specialist centre care, treatment intensity and survival), it is difficult to predict the factors that will be important a decade later. However, if these variables contributed to an increased rate of decline in $\mathrm{FEV}_{1} \%$ predicted, it does not invalidate these models as the focus is on the relationship between HRQoL and $\mathrm{FEV}_{1} \%$ predicted. The more $\mathrm{FEV}_{1} \%$ predicted declines (for whatever reason), the easier it becomes to detect the relationship between HRQoL and $\mathrm{FEV}_{1} \%$ predicted.

The future entry of HRQoL data into registries is important, although the usefulness and challenges of including HRQoL data in registries (eg, choice of HRQoL tool and domains, time interval, patient burden) requires consideration. Such data could provide evidence to support our conclusion that a decrease in lung function predicts a decrease in HRQoL over time.

Contributors JA: conception and design, analysis and interpretation of data, drafting, revising and final approval of the article. MAH: analysis and interpretation of data, drafting, revising and final approval of the article. AMM: conception and design, acquisition of data, critical revision and final approval of the article. SPC: conception and design, interpretation of data, critical revision and final approval of the article.

Competing interests None.

Ethics approval Ethics approval was obtained from Leeds research ethics committee.

Provenance and peer review Not commissioned; externally peer reviewed.

\section{REFERENCES}

1 Rosenstein BL, Zeitlin PL. Cystic fibrosis. Lancet 1998:351:277-82.

2 UK Cystic Fibrosis Registry. Annual Data Report 2010. Cystic Fibrosis Trust 2012.

3 Sawicki GS, Sellers DE, Robinson WM. High treatment burden in adults with cystic fibrosis: challenges to disease self-management. J Cyst Fibros 2009;8:91-6.
4 Sawicki GS, Tiddens H. Managing treatment complexity in cystic fibrosis: challenges and opportunities. Pediatr Pulmonol 2012;47:523-33.

5 Abbott J, Hart A, Havermans $T$, et al. Measuring health-related quality of life in clinical trials in cystic fibrosis. J Cyst Fibros 2011;10;\$82-5.

6 Abbott J, Hart A, Morton AM, et al. Can health-related quality of life predict survival in adults with cystic fibrosis. Am J Respir Crit Care Med 2009;179:54-8.

7 Quittner A, Buu A, Messer M, et al. Development and validation of the cystic fibrosis questionnaire in the United States: a health-related quality-of-life measure for cystic fibrosis. Chest 2005; 128:2347-54.

8 Goldbeck L, Schmitz TG. Comparison of three generic questionnaires measuring quality of life in adolescents and adults with cystic fibrosis: the 36-item short form health survey, the quality of life profile for chronic diseases, and the questions on life satisfaction. Qual Life Res 2001;10:23-36.

9 Gee L, Abbott J, Conway S, et al. Development of a disease specific health related quality of life measure for adults and adolescents with cystic fibrosis. Thorax 2000;55:946-54.

10 Gee L, Abbott J, Conway SP, et al. Quality of life in cystic fibrosis: the impact of gender, general health perceptions and disease severity. J Cyst Fibros 2003;2:206-13

11 Staab D, Wenninger K, Gerbert N, et al. Quality of life in patients with cystic fibrosis and their parents; what is important besides disease severity. Thorax 1998;53:727-31.

12 Bradley J, McAlister 0, Elborn S. Pulmonary function, inflammation, exercise capacity and quality of life in cystic fibrosis. Eur Respir J 2001;17:712-15.

13 Schmitz TG, Henrich G, Goldbeck L. Quality of life with cystic fibrosis-aspects of age and gender. Klinische Padiatrie 2006;218:7-12.

14 Gee L, Abbott J, Hart A, et al. Associations between clinical variables and quality of life in adults with cystic fibrosis. J Cyst Fibros 2005;4:59-66.

15 Goldbeck L, Zerrer S, Schmitz TG. Monitoring quality of life in outpatients with cystic fibrosis: feasibility and longitudinal results. J Cyst Fibros 2007;6:171-8.

16 Congleton J, Hodson ME, Duncan-Skingle F. Do Nottingham Health Profile scores change over time in cystic fibrosis? Respir Med 1998;92:268-72.

17 Sawicki GS, Rasouliyan L, McMullen AH, et al. Longitudinal assessment of health-related quality of life in an observational cohort of patients with cystic fibrosis. Pediatr Pulmonol 2011;46:36-44.

18 Que C, Cullinan P, Geddes D. Improving rate of decline of FEV1 in young adults with cystic fibrosis. Thorax 2006;61:155-7.

19 Rosenbluth DB, Wilson K, Ferkol T, et al. Lung function decline in cystic fibrosis patients and timing for lung transplantation referral. Chest 2004;126:412-19.

20 Britto MT, Kotagal UR, Hornung RW, et al. Impact of recent pulmonary exacerbations on quality of life in patients with cystic fibrosis. Chest 2002;121:64-72.

21 Arrington-Sanders R, Yi MS, Tsevat J, et al. Gender differences in health-related quality of life of adolescents with cystic fibrosis. Health Qual Life Out 2006;4:5.

22 Abbott J, Conway S, Etherington C, et al. Nutritional status, perceived body image and eating behaviours in adults with cystic fibrosis. Clin Nutr 2007;26:91-9.

23 Fitzmaurice GM, Laird NM, Ware JH. Applied longitudinal analysis. 2nd edn., New Jersey: Wiley Series in Probability, 2011

24 Kreft I, De Leeuw J. Introducing multilevel modelling. London: Sage Publications, 1998.

25 Walters SJ. Quality of life outcomes in clinical trials and health care evaluation: a practical guide to health care interpretation. Chichester: Wiley, 2009.

26 Rasbash J, Charlton C, Browne WJ, et al. MLwiN Version 2.1. Centre for multilevel modelling. University of Bristol, 2009.

27 Littlewood JM, MacDonald A. Rationale of modern dietary recommendations in cystic fibrosis. J R Soc Med 1987;80:16-24.

28 Bowling A, Bond M, Jenkinson C, et al. Short Form 36 (SF-36) Health Survey questionnaire: which normative data should be used? Comparisons between the norms provided by the omnibus survey in Britain, the Health Survey for England and the Oxford Healthy Life Survey. J Public Health Med 1999;21:255-70.

29 Suri $R$, Metcalf $C$, Wallis $C$, et al. A. Assessing the usefulness of outcomes measured in a cystic fibrosis treatment trial. Respir Med 2007;101:254-60.

30 Herrman $\mathrm{H}$, Stewart DE, Diaz-Granados $\mathrm{N}$, et al. What is resilience? Can J Psychiatry 2011;56:258-65.

31 Abbott J, Hart A, Morton A, et al. Health-related quality of life in adults with cystic fibrosis: the role of coping. J Psychosom Res 2008;64:149-57.

32 Riekert KA, Bartlett SJ, Boyle MP, et al. The association between depression, lung function, and health-related quality of life among adults with cystic fibrosis. Chest 2007;132:231-7.

33 Dasenbrook EC, Merlo CA, Diener-West M, et al. Persistent methicillin-resistant Staphylococcus aureus and rate of FEV1 decline in cystic fibrosis. Am J Respir Crit Care Med 2008:178:814-21.

34 Kalish LA, Waltz D A, Dovey M, et al. Impact of Burkholderia dolosa on lung function and survival in cystic fibrosis. Am J Respir Crit Care Med 2006;173:421-5.

35 Waters V, Stanojevic S, Atenafu EG, et al. Effect of pulmonary exacerbations on long-term lung function decline in cystic fibrosis. Eur Respir J 2012:40:61-6. 